\title{
Effects of Potential Micro- and Macro-nutrients in Combatting COVID-19
}

\author{
Jason Rocha $^{1}$ (I) Tamneet Basra $^{1} \cdot$ Bara El Kurdi $^{1} \cdot$ Carla Venegas-Borsellino $^{2}$
}

Accepted: 12 August 2021 / Published online: 30 August 2021

(C) The Author(s), under exclusive licence to Springer Science+Business Media, LLC, part of Springer Nature 2021

\begin{abstract}
Purpose of Review Gain insight on the effect of some recently studied nutrients and nutritional markers on the COVID-19 disease course.

Recent Findings In vitro studies indicate that SCFAs do not interfere with SARS-CoV-2 infectivity. Observational studies indicate that eating processed or red meat three or more times per week had overall higher risk of pneumonia. Studies suggest that markers of regular outdoor physical activity (high HDL, lack of vitamin D deficiency, lack of obesity, etc.) prevent severe complications of COVID-19. Summary Although no definitive nutrients were found to significantly alter the COVID-19 disease course, some therapeutic candidates such as calcium, vitamin D, and albumin were surmised. Other nutrients that modulate serum lipid levels, cytokine levels, and albumin levels may hold promise for prevention of morbid or fatal outcomes related to COVID-19, as does the reduction of red or processed meat consumption.
\end{abstract}

Keywords COVID-19 · Inflammation · Pneumonia · Micronutrients - Cytokine storm · Lipotoxicity · Cholesterol · Vitamin D · Calcium · Albumin

This article is part of the Topical collection on Nutrition, Metabolism, and Surgery.

Jason Rocha

rochaj3@uthscsa.edu

1 Division of Gastroenterology and Nutrition, University of Texas Health at San Antonio, San Antonio, TX, USA

2 Department of Critical Care Medicine, Mayo Clinic, Jacksonville, FL, USA

\section{Introduction}

Since the start of the COVID-19 pandemic, the World Health Organization (WHO) and Centers for Disease Control (CDC) estimate that by the end of August 2021, there will have been more than 4.48 million deaths worldwide and more than 635,000 deaths in the USA from the SARS-CoV-2 infection [1]. The true level of transmission and calculation of mortality rate is frequently underestimated. Approximately, $80 \%$ of the population remains undetected due to asymptomatic status or failure to present to health care facilities due to mild symptoms [3]. Several reports from within the U.S and worldwide cohort groups have identified groups with high-risk characteristics that contribute to a poor prognosis. In patients infected with SARS-CoV-2, disease severity and outcomes are related to the components of the inflammatory cascade and although the exact molecular mechanism is not known, empiric treatments have targeted components of this signaling cascade to reduce morbidity and mortality [2].

The COVID-19 world-wide pandemic has led to huge financial implications with the closure of major businesses and travel. The healthcare system was burdened beyond capacity with a lack of resources and a sudden surge in unemployment left many Americans without employersponsored insurance [4]. The viability of a number of hospitals and office-based practices were threatened, leading to the closure of several private practices nationwide. In the first few months of the pandemic, office-based practices had reductions of $60 \%$ in volume with a loss of more than 1 million jobs in the health care system [4]. The American Hospitals Association estimated a loss of over $\$ 323$ billion at the end of the first year due to the pandemic [4]. However, with recurrent surges, utilization of novel therapies, and development and distribution of the COVID- 
19 vaccine, the true financial costs of COVID-19 on American healthcare continue to grow.

It is prudent for any healthcare provider to consider the impact of widely available nutrients on altering the infectious disease course when making recommendations to atrisk patients or populations during a pandemic. This information is especially valuable for populations who might not have access to affordable healthcare, novel investigational therapies, or sufficient biomedical equipment.

\section{Inflammatory Response to SARS-CoV-2 Infection}

In the process for controlling and resolving the infection by the SARS-CoV-2, an induction of a complex immune response occurs that involves all the immune system components. Once the presence of the virus is recognized by the innate system, the immune response is initiated by production of pro-inflammatory cytokines which activates the specific adaptive response. That response includes natural T-cell killers and the production of specific antibodies by B-cells. These cytokines also amplify the inflammatory response by attracting macrophages and neutrophils, but the imbalance appears to be related to a severe COVID-19 disease course.

The severe inflammatory response seen in COVID-19 is usually characterized by lymphopenia and malfunction of lymphocytes, monocytes, and granulocytes. This increases the possibility of a subsequent superinfection by other micro-organisms and ultimately multi-organ failure [5].

\section{Risk Factors and the Natural History of COVID- 19-Related Inflammation/ARDS}

The infection by SARS-CoV-2 is characterized by multiple manifestations, ranging from completely asymptomatic to mild common cold-type-related symptoms, which represents most patients (about $80 \%$ with myalgia, prolonged fever, diarrhea, and neurological symptoms like anosmia and hypogeusia), to moderate (15\%), and severe $(5 \%)$ disease characterized by acute respiratory and multiorgan failure which can lead to death. The infection can affect any age group or sex, but most commonly affect patients who are of advanced age, immunocompromised, obese, and/or have respiratory and cardiovascular comorbidities; this group of patients carries the greatest mortality rate.

\section{Pathophysiology}

The infection is acquired when an infected individual expels micro-droplets of respiratory secretions full of viral particles which can be sustained in the air or deposited in fomites, until they contact the respiratory tract of a susceptible individual. When the virus contacts the bronchial epithelium, its port of entry is the type-II ACE2 + pneumocytes receptor whose expression becomes inhibited and allows the angiotensin II free to bind the AT1aR receptor, generating acute lung damage and its manifestation, severe acute respiratory syndrome (SARS) [5]. The main characteristic of acute respiratory distress syndrome (ARDS) seen in SARS is the peripheral depletion of T-cells, which appears to be a crucial factor in crosstalk between immune homeostasis and microbial overload, and can be used as a prognosis factor related to disease progression and severity.

\section{Inflammatory Cytokines}

Another characteristic seen in COVID-19 infection is an unbalanced or excessive immune response known as cytokine release syndrome, which is related to shock state, ARDS, multiorgan organ failure, and potentially death in patients with severe COVID-19. During this cytokine storm, the production of all pro-inflammatory elements can be elevated: IL-1 $\beta$, IL-2, IL-6, IL-7, IL-8, IL-10, granulocyte colony-stimulating factor (G-CSF), granulocytemacrophage colony-stimulating factor (GM-CSF), interferon-inducible protein-10 (IP10), monocyte chemotactic protein 1 (MCP1), macrophage inflammation protein-1 $\alpha$, IFN- $\gamma$, and TNF- $\alpha$; but the most commonly elevated in severe cases are IL-1 $\beta$, IL-6, and IL-10. There is a correlation between the elevation of these inflammatory cytokines and acute lung injury and mortality, which can represent a prognosis factor and a therapeutic option for patients with severe disease [6].

The cytokine storm is a complex process where, after SARS-CoV-2 is recognized by the innate immune system, CD4 + T cells are activated into T helper $(\mathrm{Th}) 1$ cells which release GM-CSF and induces CD14 + CD16 + monocytes with high IL-6 levels to favor local inflammation and stimulates CD14 + IL-1 $\beta+$ monocytes which increase IL-1 $\beta$ production. The sustaining of the cytokine cascades is related to Th17 which produces IL-17 to recruit more monocytes, macrophages, and neutrophils to the site of infection [6]. 


\section{Lipotoxicity and Lipid Mediators of Inflammation}

Cholesterol homeostasis is integral in maintaining cellular wellness due to its function in maintaining membrane integrity and modulating its fluidity and segregation. It plays an important role in regulating immune function and equilibrating the inflammatory process. As SARS-CoV-2 is a single-stranded RNA virus surrounded by a lipid envelop, it initially requires a lipid attachment to the membrane of the targeted cell to then proceed with fusion and endocytosis. Lipid raft microdomains serve as a deck for virus entrance and delivery of viral genome and can facilitate this pathological process when the concentration of the lipid rafts receptors is increased. Membrane composition and homeostasis influence the susceptibility of developing viral infections and it has been proposed that elevated plasma cholesterol levels can play an important role in infection by SARS-CoV-2, likewise low cholesterol levels can reduce its infectivity. Studies in vitro have shown that depletion of membrane-bound cholesterol ACE2-expressing cells reduces the SARS-CoV-2 binding capacity for the spike protein by $50 \%\left[7^{\circ}\right]$.

Cholesterol and fatty acid homeostasis also modulate viral infectivity by enhancing viral fusion when the Cholesterol/fatty acid ratio in the cellular membrane is elevated and by inhibiting its entrance with the appropriate presence of 25- and 27-hydroxycholesterol. In cases of moderate and severe COVID-19 infection, there have been reports of patient serum levels lower than $50 \%$ of normal for hydroxycholesterols, lanosterol, lathosterol, and desmosterol, all precursors of cholesterol. HDL particles, known to adapt to acute inflammatory conditions such as during the cytokine storm, can have an antiviral effect independent of their lipid envelope [7•]. Critically low HDL serum levels have been reported in severe COVID-19 patients. Although there is a clear relationship between the composition of lipid rafts and the infectivity and severity of SARS-CoV-2 infection, more research should be made in this area to avoid unsupported pathological and clinical implications.

\section{Meat Consumption}

Pneumonia is the most common high-risk complication of COVID-19 [35]. Macronutrient consumption might contribute to propensity of acquiring pneumonia. The UK Biobank study collected information on meat intake at baseline for 474,985 middle-aged adults and linked it to hospital admissions and mortality data. Participants who reported consuming red or processed meat three or more times per week had, on average, higher risk of pneumonia
(HR 1.31, 1.18-1.44). Of note, these participants were more likely to smoke and consume alcohol and more poultry meat and consume less fruit and vegetables, fiber, and fish compared to the participants who consumed meat less than three times per week [30॰]. Increased BMI observed to be associated with red and processed meat consumption might have caused residual confounding. However, another study found that higher intake of red meat was associated with a higher risk of death due to respiratory disease, including pneumonia [30].

\section{Prebiotics and Short-Chain Fatty Acids}

Short-chain fatty acids (SCFAs) such as butyrate have been demonstrated to mediate host-microbiota interaction in regard to regulating mucosal permeability and immune response. Starch, arabinoxylan-rich whole grains, and brans from cereals serve as substrates that stimulate the colonic microbial production of butyrate [32]. Because SARS-CoV-2 infection was shown to change microbiota and SCFA production, Pascoal et al. investigated in vitro the impact of SCFAs in the infection of human intestinal biopsies and intestinal epithelial cells by SARS-CoV-2. No change in entry or replication or release of SARS-CoV-2 in intestinal cells was found [34•]. Other studies have shown that butyrate increases cellular infection by $\mathrm{H} 1 \mathrm{~N} 1$ influenza A virus, reovirus, and human immunodeficiency virus 1 (HIV-1) due to suppression of specific antiviral interferonstimulated genes [34]. Despite the lack of evidence that SCFAs interfere with SARS-CoV-2 infectivity or the suggestion that SCFAs might allow for increased viral loads, there may be other mechanisms by which prebiotics or SCFAs mitigate the harmful complications of COVID-19 related to inflammation and thrombosis.

\section{Vitamin D}

Vitamin D is a fat-soluble vitamin which has been linked to numerous immunological effects including supporting the induction of antimicrobial peptides, inducing autophagy, and aiding the synthesis of reactive nitrogen and oxygen intermediates [8-11]. Vitamin D deficiency has been shown to be associated with increased incidence of respiratory infections [12•]. In the context of COVID-19, multiple studies have proposed that vitamin D is protective from acquiring the infection and that vitamin D supplementation might be effective in reducing disease transmission [12]. Other studies have also proposed that vitamin D deficiency is associated with increased severity of COVID-19 infection [13, 14]. While the majority of these studies are underpowered and suffer from methodological 
weaknesses, the evidence still suggests that vitamin D supplementation is a safe, cheap intervention which may be reasonable for use by patients at high-risk of COVID-19 infection [15]; however, it is possible that the health benefits attributed to sufficient levels of vitamin D might be associated with sufficient time spent on outdoor physical activity.

\section{Calcium}

While hypocalcemia is common in critically ill patients [16] and is often attributed to factors such as vitamin D deficiency, hypoproteinemia, hypomagnesemia, and drug interaction [16], the association of hypocalcemia with increased severity of COVID-19 infection cannot be overlooked. Hypocalcemia has been linked with worse outcomes in various diseases [16, 17], most recently COVID-19 [18-20]. While calcium might seem like an irrelevant bystander, its effects can be massive through different biochemical pathways; most recently, studies have suggested that serum calcium can exert its anti-inflammatory effects by neutralizing free fatty acids in the serum of sick patients, ameliorating lipotoxicity effects, and preventing end-organ failure [21-23]. Based on previous studies indicating calcium supplementation was able to reduce systemic inflammatory response, CRP levels, and local complications [25•], the aforementioned studies have proposed that calcium supplementation should be tested as a therapeutic intervention to prevent the transformation from mild to severe COVID-19 infection.

\section{Albumin}

Serum albumin is a major plasma protein and indicator of morbidity and mortality, and recovery from acute and chronic disease [36, 37]. It is integral in maintaining intravascular oncotic pressure, carrying hydrophobic substances, participating in acid-base balance, and preventing platelet aggregation [25]. It is often misused as a surrogate marker of nutritional status in hospitalized patients [26]. Hypoalbuminemia has been associated with worse outcomes in hospitalized patients in various diseases including almost all organ systems [27]. Hypoalbuminemia has multiple proposed etiologies including underproduction due to malnutrition or decreased hepatic synthesis in liver disease or under the influence of inflammatory mediators, increased consumption during inflammatory and catabolic states and albumin loss in urine or through vascular leak. Severe COVID-19 is associated with reduced serum albumin, a finding seen in multiple studies since the onset of the pandemic [29•]. Albumin supplementation has been a recurrent source of controversy over the past few decades with conflicting evidence. Its use has mostly been dependent on clinicians' anecdotal evidence and personal opinion. Recently, studies have suggested that a temporal factor might be in play in the supplementation of serum albumin [21] with early supplementation resulting in a superior effect over late supplementation. While the controversy over albumin supplementation continues, albumin supplementation appears to be a safe and affordable intervention to be tested either by direct supplementation or by optimizing nutritional support to induce hepatic synthesis of albumin.

\section{Ongoing Studies}

Currently, there are human clinical trials ongoing looking at the effects of fish oil, olive oil, EPA/DHA, omega-3 fatty acids, Mediterranean diet, exercise, wine, and plant extract supplements on platelet-activating factor (PAF), its catabolic enzymes, and its effect on platelet aggregation. In hopes that micronutrient platelet aggregating factor inhibitors stem the harmful effects of COVID-19-related inflammation and thrombosis, investigators are continuing to study the effects of vitamin C, vitamin D, vitamin B12, zinc, fish oil, quercetin, honey, and others on COVID-19 [31].

\section{Conclusion}

As the search for effective treatments for COVID-19 continues, specific micronutrients and macronutrients may influence the severity of infectivity, symptoms, and outcomes related to this disease. While the data may show some promise for modulation of albumin, cholesterol, and circulating inflammatory cytokines by consuming more or less of a specific micro- or macro-nutrient, the available evidence is observational and may simply support the fact that obesity is an independent risk factor for poor outcomes when ill with COVID-19. Further research including prospective human clinical trials is needed to determine the most effective dietary recommendations for the prevention and treatment of COVID-19 and its complications. 
Summary of dietary and lifestyle recommendations (apart from the CDC recommendations) to increase odds of survival from COVID-19 infection

\begin{tabular}{|c|c|c|c|}
\hline $\begin{array}{l}\text { Serological } \\
\text { marker }\end{array}$ & Goal & Pertinent Studies & General Recommendation \\
\hline Albumin & $\begin{array}{l}\text { Avoid } \\
\text { hypoalbuminemia }\end{array}$ & Aziz et al. 2020 & $\begin{array}{l}\text { Eat a well-balanced diet with at least } 1 \mathrm{~g} / \mathrm{kg} \text { of body weight protein } \\
\text { per day. }\end{array}$ \\
\hline Cholesterol & $\begin{array}{l}\text { Avoid high } \\
\text { cholesterol }\end{array}$ & Kočar et al. 2021 & $\begin{array}{l}\text { Enjoy moderate physical activity for at least } 30 \text { min per day and a diet } \\
\text { low in cholesterol. Take cholesterol medication if advised by your } \\
\text { doctor. }\end{array}$ \\
\hline $\begin{array}{l}\text { Inflammatory } \\
\text { cytokines }\end{array}$ & $\begin{array}{l}\text { Avoid triggers of } \\
\text { inflammation }\end{array}$ & García et al. 2020 & $\begin{array}{l}\text { Enjoy an anti-inflammatory diet that includes fruits, vegetables, whole } \\
\text { grains, and foods containing omega- } 3 \text { fatty acids. Avoid eating red } \\
\text { or processed meat. }\end{array}$ \\
\hline Vitamin D & $\begin{array}{l}\text { Avoid Vitamin D } \\
\text { deficiency }\end{array}$ & $\begin{array}{l}\text { Martineau et al. 2017, Pereira } \\
\text { et al. 2020, Radujkovic et al. } \\
2020\end{array}$ & $\begin{array}{l}\text { Expose as much of your skin as possible to direct sunlight for at least } \\
15 \text { min per day. Avoid sunburn. Take vitamin D supplement if } \\
\text { advised by your doctor. }\end{array}$ \\
\hline
\end{tabular}

Author contributions Jason Rocha, Carla Venegas-Borsellino, Tamneet Basra, and Bara El Kurdi had equal part in conception, literature review, and writing.

Funding The authors received no funding for this project.

Availability of data and material Not applicable. Code availability Not applicable.

\section{Declarations}

Conflict of interest The authors have no relevant financial or nonfinancial interests to disclose. The authors have no conflicts of interest to declare that are relevant to the content of this article. All authors certify that they have no affiliations with or involvement in any organization or entity with any financial interest or non-financial interest in the subject matter or materials discussed in this manuscript. The authors have no financial or proprietary interests in any material discussed in this article.

Consent to participate Not applicable.

Consent for publication All authors consent to publication of this manuscript.

Ethics approval Not applicable.

\section{References}

Recently published papers of particular interest have been highlighted as:

- Of importance

1. https://covid19.who.int/ and https://covid.cdc.gov/covid-datatracker/.

2. Ragab D, Salah Eldin H, Taeimah M, Khattab R, Salem R. The COVID-19 cytokine storm; what we know so far. Front Immunol. 2020;11:1446. https://doi.org/10.3389/fimmu.2020.01446.
3. Baud D, Qi X, Nielsen-Saines K, Musso D, Pomar L, Favre G. Real estimates of mortality following COVID-19 infection. Lancet Infect Dis. 2020;20(7):773. doi: https://doi.org/10.1016/ S1473-3099(20)30195-X. Epub 2020 Mar 12.

4. COVID-19 - Implications for the Health Care System. N Engl J Med. 2020;383(17):1698. https://doi.org/10.1056/NEJMx200018. Epub 2020 Jul 23. Erratum for: $N$ Engl J Med. 2020;383(15):1483-1488.

5. Yang L, Liu S, Liu J, Zhang Z, Wan X, Huang B, Chen Y, Zhang Y. COVID-19: immunopathogenesis and Immunotherapeutics. Signal Transduct Target Ther. 2020;5(1):128. https://doi.org/10. 1038/s41392-020-00243-2.

6. García LF. Immune response, inflammation, and the clinical spectrum of COVID-19. Front Immunol. 2020;16(11):1441. https://doi.org/10.3389/fimmu.2020.01441.

7. •Kočar E, Režen T, Rozman D. Cholesterol, lipoproteins, and COVID-19: basic concepts and clinical applications. Biochim Biophys Acta Mol Cell Biol Lipids. 2021;1866(2):158849. https://doi.org/10.1016/j.bbalip.2020.158849. Epub 2020 Nov 4. Low cholesterol levels and elevated HDL levels can prevent viral infection.

8. Hansdottir S, Monick MM, Hinde SL, Lovan N, Look DC, Hunninghake GW. Respiratory epithelial cells convert inactive vitamin $\mathrm{D}$ to its active form: potential effects on host defense. J Immunol. 2008;181(10):7090-9. https://doi.org/10.4049/ jimmunol.181.10.7090.

9. Olliver M, Spelmink L, Hiew J, Meyer-Hoffert U, HenriquesNormark B, Bergman P. Immunomodulatory effects of vitamin D on innate and adaptive immune responses to Streptococcus pneumoniae. J Infect Dis. 2013;208(9):1474-81. https://doi.org/ 10.1093/infdis/jit355. Epub 2013 Aug 6.

10. Greiller CL, Martineau AR. Modulation of the immune response to respiratory viruses by vitamin D. Nutrients. 2015;7(6):4240-70. https://doi.org/10.3390/nu7064240.

11. Hewison M. Antibacterial effects of vitamin D. Nat Rev Endocrinol. 2011;7(6):337-45. https://doi.org/10.1038/nrendo.2010. 226. Epub 2011 Jan 25. Erratum in: Nat Rev Endocrinol. 2011;7(8):436.

12. Martineau AR, Jolliffe DA, Hooper RL, Greenberg L, Aloia JF, Bergman P, Dubnov-Raz G, Esposito S, Ganmaa D, Ginde AA, Goodall EC, Grant CC, Griffiths CJ, Janssens W, Laaksi I, Manaseki-Holland S, Mauger D, Murdoch DR, Neale R, Rees JR, Simpson S Jr, Stelmach I, Kumar GT, Urashima M, Camargo CA Jr. Vitamin D supplementation to prevent acute respiratory tract 
infections: systematic review and meta-analysis of individual participant data. BMJ. 2017;356:i6583. https://doi.org/10.1136/ bmj.i6583. Vitamin D deficiency is associated with increased incidence of respiratory infections.

13. Mercola J, Grant WB, Wagner CL. Evidence regarding vitamin D and risk of COVID-19 and its severity. Nutrients. 2020;12(11):3361. https://doi.org/10.3390/nu12113361.

14. Radujkovic A, Hippchen T, Tiwari-Heckler S, Dreher S, Boxberger M, Merle U. Vitamin D deficiency and outcome of COVID-19 patients. Nutrients. 2020;12(9):2757. https://doi.org/ 10.3390/nu12092757.

15. Pereira M, Dantas Damascena A, Galvão Azevedo LM, de Almeida OT, da Mota SJ. Vitamin D deficiency aggravates COVID-19: systematic review and meta-analysis. Crit Rev Food Sci Nutr. 2020;4:1-9. https://doi.org/10.1080/10408398.2020. 1841090.

16. Zemb P, Bergman P, Camargo CA Jr, Cavalier E, Cormier C, Courbebaisse M, Hollis B, Joulia F, Minisola S, Pilz S, Pludowski P, Schmitt F, Zdrenghea M, Souberbielle JC. Vitamin D deficiency and the COVID-19 pandemic. J Glob Antimicrob Resist. 2020;22:133-134. https://doi.org/10.1016/j.jgar.2020.05.006. Epub 2020 May 29.

17. Kelly A, Levine MA. Hypocalcemia in the critically ill patient. J Intensive Care Med. 2013;28(3):166-77. https://doi.org/10. 1177/0885066611411543. Epub 2011 Aug 12.

18. Ammori BJ, Barclay GR, Larvin M, McMahon MJ. Hypocalcemia in patients with acute pancreatitis: a putative role for systemic endotoxin exposure. Pancreas. 2003;26(3):213-7. https://doi.org/10.1097/00006676-200304000-00001.

19. Sun JK, Zhang WH, Zou L, Liu Y, Li JJ, Kan XH, Dai L, Shi QK, Yuan ST, Yu WK, Xu HY, Gu W, Qi JW. Serum calcium as a biomarker of clinical severity and prognosis in patients with coronavirus disease 2019. Aging (Albany NY). 2020;12(12):11287-11295. https://doi.org/10.18632/aging. 103526. Epub 2020 Jun 25.

20. Liu J, Han P, Wu J, Gong J, Tian D. Prevalence and predictive value of hypocalcemia in severe COVID-19 patients. J Infect Public Health. 2020;13(9):1224-1228. https://doi.org/10.1016/j. jiph.2020.05.029. Epub 2020 Jun 22.

21. Di Filippo L, Formenti AM, Rovere-Querini P, Carlucci M, Conte C, Ciceri F, Zangrillo A, Giustina A. Hypocalcemia is highly prevalent and predicts hospitalization in patients with COVID-19. Endocrine. 2020;68(3):475-478. https://doi.org/10. 1007/s12020-020-02383-5. Epub 2020 Jun 12.

22. El-Kurdi B, Khatua B, Rood C, Snozek C, Cartin-Ceba R, Singh VP. Lipotoxicity in COVID-19 Study Group. Mortality from coronavirus disease 2019 increases with unsaturated fat and may be reduced by early calcium and albumin supplementation. Gastroenterology. 2020;159(3):1015-1018. https://doi.org/10. 1053/j.gastro.2020.05.057. Epub 2020 May 27.

23. Singh VP, Khatua B, El-Kurdi B, Rood C. Mechanistic basis and therapeutic relevance of hypocalcemia during severe COVID-19 infection. Endocrine. 2020;70(3):461-2. https://doi.org/10.1007/ s12020-020-02530-y. Epub 2020 Oct 24.

24. Singh VP, Khatua B, El-Kurdi B. Hypocalcemia and hypoalbuminemia during COVID-19 infection: Opportunities for therapeutic intervention. J Infect Public Health. 2020;13(12):1887. https://doi.org/10.1016/j.jiph.2020.09.019. Epub 2020 Oct 10.

25. - Khatua B, Yaron JR, El-Kurdi B, Kostenko S, Papachristou GI, Singh VP. Ringer's lactate prevents early organ failure by providing extracellular calcium. J Clin Med. 2020;9(1):263. https:// doi.org/10.3390/jcm9010263. Calcium supplementation is able to reduce systemic inflammatory response, CRP levels and local complications of infection.
26. Limaye K, Yang JD, Hinduja A. Role of admission serum albumin levels in patients with intracerebral hemorrhage. Acta Neurol Belg. 2016;116(1):27-30. https://doi.org/10.1007/s13760015-0504-2. Epub 2015 Jul 2.

27. Sung J, Bochicchio GV, Joshi M, Bochicchio K, Costas A, Tracy $\mathrm{K}$, Scalea TM. Admission serum albumin is predicitve of outcome in critically ill trauma patients. Am Surg. 2004;70(12):1099-102.

28. Akirov A, Masri-Iraqi H, Atamna A, Shimon I. Low albumin levels are associated with mortality risk in hospitalized patients. Am J Med. 2017;130(12):1465.e11-1465.e19. https://doi.org/10. 1016/j.amjmed.2017.07.020. Epub 2017 Aug 9. Erratum in: Am J Med. 2020;133(5):646.

29. • Aziz M, Fatima R, Lee-Smith W, Assaly R. The association of low serum albumin level with severe COVID-19: a systematic review and meta-analysis. Crit Care. 2020;24(1):255. https://doi. org/10.1186/s13054-020-02995-3. Severe COVID-19 is associated with reduced serum albumin.

30. • Papier K, Fensom G, Knuppel A, Appleby P, Tong T, Schmidt J, Travis R, Key T, Perez-Cornago A. Meat consumption and risk of 25 common conditions: outcome-wide analysis in 475,000 men and women in the UK Biobank study. BMC Med. 2021;19:53. https://doi.org/10.1186/s12916-021-01922-9. Meat consumption is linked to increased risk of pneumonia.

31. Bradbury KE, Young HJ, Guo W, Key TJ. Dietary assessment in UK Biobank: an evaluation of the performance of the touchscreen dietary questionnaire. J Nutritional Sci. 2018;7: e6. https://doi. org/10.1017/jns.2017.66.

32. Detopoulou P, Demopoulos CA, Antonopoulou S. Micronutrients, phytochemicals and Mediterranean diet: a potential protective role against COVID-19 through modulation of PAF actions and metabolism. Nutrients. 2021;13:462. https://doi.org/ 10.3390/nu13020462.

33. Bach Knudsen KE, Lærke HN, Hedemann MS, Nielsen TS, Ingerslev AK, Gundelund Nielsen DS, Theil PK, Purup S, Hald S, Schioldan AG, Marco ML, Gregersen S, Hermansen K. Impact of diet-modulated butyrate production on intestinal barrier function and inflammation. Nutrients. 2018;10(10):1499. https://doi.org/ 10.3390/nu10101499.

34. - Pascoal LB, Rodrigues PB, Leal RF, et al. Microbiota-derived short-chain fatty acids do not interfere with SARS-CoV-2 infection of human colonic samples. Gut Microbes 2021;13:1, 1-9. https://doi.org/10.1080/19490976.2021.1874740. In vitro studies indicate that SCFAs do not interfere with SARS-CoV-2 infectivity.

35. Chemudupati M, Kenney AD, Smith AC, Fillinger RJ, Zhang L, Zani A, Liu S-L, Anderson MZ, Sharma A, Yount JS. Butyrate reprograms expression of specific interferon-stimulated genes. J Virol. 2020;94:e00326-e420. https://doi.org/10.1128/JVI. 00326-20.

36. Murk W, Gierada M, Fralick M, Weckstein A, Klesh R, Rassen JA. Diagnosis-wide analysis of COVID-19 complications: an exposure-crossover study. CMAJ. 2021;193(1):10-8. https://doi. org/10.1503/cmaj.201686.

37. Fuhrman MP, Charney P, Mueller CM. Hepatic proteins and nutrition assessment. J Am Diet Assoc. 2004;104(8):1258-64.

38. Academy of Nutrition and Dietetics. Pocket guide to nutrition assessment. 3rd ed. Chicago, IL: Academy of Nutrition and Dietetics; 2016. p. 104-6.

Publisher's Note Springer Nature remains neutral with regard to jurisdictional claims in published maps and institutional affiliations. 